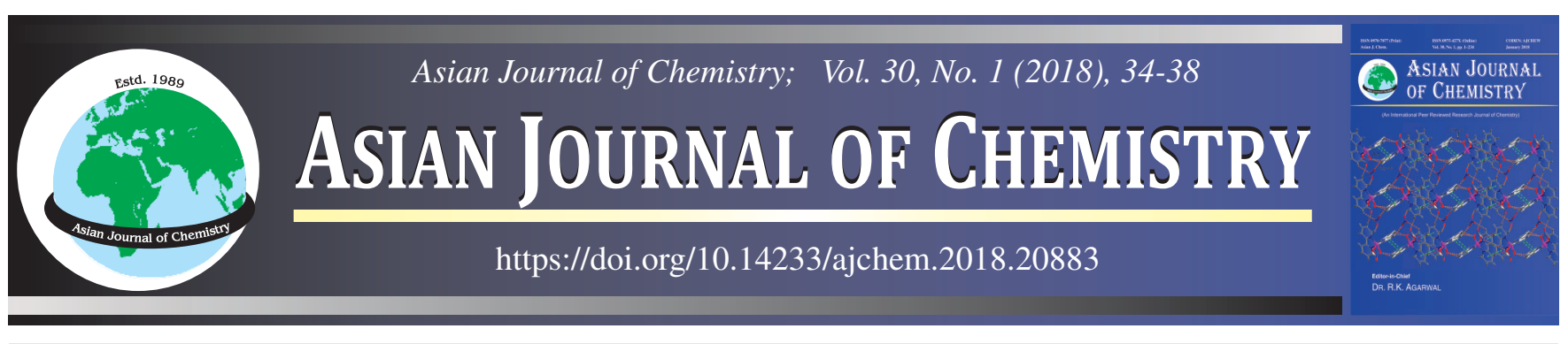

\title{
Enhanced Visible Light Photocatalytic Activity of Lead Selenide/Graphene/Titanium Dioxide Nanocomposite Synthesized via Ultra-Sonication Technique
}

\author{
Asghar Ali and Won-Chun OH*
}

Department of Advanced Materials Science \& Engineering, Hanseo University, Seosan 31962, Republic of Korea

*Corresponding author: Fax: +82 41 6883352; Tel: +82 41 6601337; E-mail: wc_oh@ hanseo.ac.kr

\begin{abstract}
In this study, we investigated the photo-degradation efficiency of $\mathrm{PbSe}-\mathrm{G}-\mathrm{TiO}_{2}$ ternary nanocomposite under visible light irritation using rhodamine B as standard dye, A nanocomposite was synthesized by ultra-sonication technique and characterized by X-ray diffraction, scanning electron microscopy, transmission electron microscopy, Raman spectroscopic analysis and UV-visible absorbance spectra analysis. The results indicate that $\mathrm{PbSe}-\mathrm{G}-\mathrm{TiO}_{2}$ ternary nanocompsite has excellent stability and good photodegradation efficiency than PbSe-G and $\mathrm{TiO}_{2}-\mathrm{G}$ nanocomposite which is approximately $92.5 \%$ of rhodamine $\mathrm{B}$ degradation after visible light irradiation for $180 \mathrm{~min}$.

Keywords: Graphene, Photocatalytic activity, Nanocomposite, PbSe-G-TiO ${ }_{2}$, Rhodamine B dye.
\end{abstract}

\section{INTRODUCTION}

Textile industries are major cause of an environmental population, not only utilize large amount of water but also produce enormous volume of wastewater during the dyeing processes [1]. It consists of highly intense colored and other contaminated substance and these wastewater are not ignorable, because its direct or indirect effected to human as well as aquatic life. Therefore, textile dyeing wastewater treatment has received more attention in the last few decades [2-4]. Different techniques are used for removing hydrophobic dyes, such as electron oxidation, ozonation, electro-kinetic coagulation ion, membrane filtration and microbial degradation [5-10]. These techniques have some advantages and disadvantages over the other techniques. Therefore suitable techniques are required to use to degrade the dye form water. among of these techniques heterogeneous photocatalysis by semiconductors materials as favourable techniques and been extensively used for the removal of toxic dyes, due to their well-defined electrochemistry, excellent redox recyclability and outstanding environmental stability, therefore researcher choose photocatalytic degradation technique to eliminate dyes form wastewater [11-14]. Recently $\mathrm{TiO}_{2}$ has been used for the photo-degradation due to their exclusive properties, such as excellent chemical stability, nontoxicity, inexpensive and high photocatalytic efficiency [15]. However, the uses of $\mathrm{TiO}_{2}$ still limit due to its high energy band gap $(3.2 \mathrm{eV})$ and fast recombination of electron hole pair, the photo generated electron and holes in the excited states are unstable and promptly recombine, dissipating the input energy as heat resulting minimize photocatalytic efficiency [16-18]. Therefore to increase the efficiency of $\mathrm{TiO}_{2}$ some modification are carried out, i.e. doping $\mathrm{TiO}_{2}$ with metal $[19,20]$ and non-metal $[21,22]$ or coupling $\mathrm{TiO}_{2}$ with narrow band gap semiconductors [23,24] and coupling with carbon nano material i.e. grapheme [25]. Graphene flat monolayer structure and widely investigated for its intriguing electrical and mechanical properties [26-28]. Furthermore graphene great ability by anchoring nanoparticles, i.e. PbSe and improve their photocataytic efficiency and overcome recombination process. Many synthesis techniques such as hydrothermal, microwave and sol-gel have been developed to attachment of nanoparticles on the graphene sheets [29,30]. In present work, we prepare $\mathrm{PbSe}-\mathrm{G}-\mathrm{TiO}_{2}$ photocatalyst by an ultra-sonication technique. The prepared samples are used for photo-degradation. The photo catalytic activities were tested with rhodamine B as a standard dye under visible light irradiation.

\begin{tabular}{l} 
EXPERIMENTAL \\
\hline Graphene oxide prepared from pure graphite in the labo- \\
ratory by the Hummers-Offeman method [31,32]. Selenium \\
powder $(99 \%)$, ammonium hydroxide $(25-28 \%)$ and titanium \\
$n$-butoxide (TNB, $\left.\mathrm{C}_{16} \mathrm{H}_{36} \mathrm{O}_{4} \mathrm{Ti}\right)$ were purchased from Samchun \\
Pure Chemical. Sodium sulfite and ethyl alcohol (94\%) were \\
purchased from Duksan Pure Chemical Co. Ltd. Lead chloride \\
and ammonium hydroxide ( $28 \%$ ) was purchased from Junsci \\
Chemical Co. Ltd., Korea. All chemicals were used without \\
further purification and all dilutions were carried out using \\
distilled water.
\end{tabular}


Synthesis of lead selenide: PbSe was synthesized through ultra-sonic technique, in synthesis procedure; $1.5 \mathrm{~g}$ of anhydrous sodium sulfite and $0.20 \mathrm{~g}$ of crude selenium powder were continuously stirred with $150 \mathrm{~mL}$ of ethylene glycol providing constant temperature of $70^{\circ} \mathrm{C}$ to form $\mathrm{Na}_{2} \mathrm{SeSO}_{3}$. After that $1 \mathrm{~mL}$ of both $\mathrm{Na}_{2} \mathrm{SeSO}_{3}$ and $\mathrm{PbCl}_{2}$ were mixed and solution were ultrasonicated using a digital sonifer for $2 \mathrm{~h}$ at $90^{\circ} \mathrm{C}$. Finally, $\mathrm{PbSe}$ precipitates were obtained using $47 \mathrm{~mm}$ Whatman filter paper. The residue was washed off with distilled water, at least five times. The collected $\mathrm{PbSe}$ power was dried in vacuum oven at a temperature of $80^{\circ} \mathrm{C}$ for $10 \mathrm{~h}$.

Synthesis of binary PbSe-G and ternary PbSe-G-TiO composites: In this process, $\mathrm{PbSe}$ particles and $200 \mathrm{mg}$ of graphene oxide (previously obtained by the Hummers-Offeman method) with a ratio of 1:1 (wt:wt) were dissolved in $150 \mathrm{~mL}$ of ethylene glycol. Then the solution was ultrasonicated for $2 \mathrm{~h}$ at $80{ }^{\circ} \mathrm{C}$. After ultra-sonication the graphene oxide was reduced to graphene nanosheet and $\mathrm{PbSe}$ compounds were grown on the graphene surface. The solution was filter with $47 \mathrm{~mm}$ Whatman filter paper with a pore size of $0.7 \mathrm{~mm}$ and then cool and settle at room temperature. The resultant powder was washed with distilled water 3 times, followed by drying in the vacuum oven. The powder was heated to $100{ }^{\circ} \mathrm{C}$ for $8 \mathrm{~h}$ in vacuum oven, to complete the formation of $\mathrm{PbSe}-\mathrm{G}$ composite nanostructures. Same procedure was followed for the syntheses of ternary $\mathrm{PbSe}-\mathrm{G}-\mathrm{TiO}_{2}$. Different concentration TNB was mixed to the PbSe-G and the solution was sonicated at room temperature for $3 \mathrm{~h}$ using a controllable serial-ultrasonic apparatus (Ultrasonic Processor, VCX 750, Korea). The final product was heat treated at $500{ }^{\circ} \mathrm{C}$ for $2 \mathrm{~h}$ in an electric furnace. The prepared sample was labeled $\mathrm{PbSe}-\mathrm{G}-\mathrm{TiO}_{2}$.

Photocatalytic degradation experiment of rhodamine B: The adsorption and photocatalytic performance of the asprepared $\mathrm{PbSe}-\mathrm{G}-\mathrm{TiO}_{2}$ was investigated by the degradation of rhodamine B dye under visible light. First $30 \mathrm{mg}$ of PbSe-G$\mathrm{TiO}_{2}$ catalytic sample was put on $100 \mathrm{~mL}$ solution of rhodamine B $\left(2.5 \times 10^{-6} \mathrm{~mol} / \mathrm{L}\right)$. In order to reach adsorption-desorption equilibrium, the solution was kept in dark for $2 \mathrm{~h}$. Then $10 \mathrm{~mL}$ sample was collected from the solution and kept in a centrifuge at $10,000 \mathrm{rpm}$ for the elimination of solid materials. After that, the light source was turn on. The samples were collected in every $30 \mathrm{~min}$ and then centrifuged for $10 \mathrm{~min}$ to remove any suspended solid. All the samples were irradiated for $180 \mathrm{~min}$ to compare their catalytic efficiencies.

Characterization: X-ray diffraction (Shimadzu XD-D1, Uki, Kumamoto, Japan) was used to describe the crystallinity of the composite with monochromatic high-intensity $\mathrm{CuK}_{\alpha}$ radiation $(\lambda=1.5406 \AA$ ). SEM (JSM-5600, JEOL Ltd., Tokyo, Japan) was used to examine the surface morphology of the $\mathrm{PbSe}-\mathrm{G}_{-} \mathrm{TiO}_{2}$ nanocomposite. Transmission electron microscopy (TEM, JEOL, JEM-2010, Japan) was used to explain the state and particle size of the prepared composite and Raman spectra of the prepared samples were observed using a spectrometer (Jasco Model Name NRS-3100) with an excitation laser wavelength of $532.06 \mathrm{~nm}$. The photocatalytic performance of the prepared samples was investigated by absorbance spectrometry whit a UV/visible spectrophotometer (Optizen POP, Mecasys, Korea).

\section{RESULTS AND DISCUSSION}

Phase structure of prepared nanocomposite was examined by XRD technique. Fig. 1 displays the XRD pattern of PbSeG-TiO ${ }_{2}$, which exhibit that the diffraction peaks of the PbSe$\mathrm{G}$ around $2 \theta$ of $29.60,43.00,48.50,53.00,60.80,76.00,69.00$ and $77.70^{\circ}$, which can be indexed to the characteristic plane reflections (200), (220), (311), (222), (400), (331), (420) and (442) reflection that correspond to the clausthalite crystal phase (JCPDS PDF\# 00-065-0327) [33]. While $\mathrm{TiO}_{2}$ are $2 \theta=26.30$, $37.94,54.56$ and 80.88 corresponding to the (111), (004), (105) and (224) diffractions as anatase crystal phase (JCPDS PDF\#00-021-1272) [34]. After the attachment of PbSe on the graphene nanosheet a small intensity peaks at $2 \theta=26.2^{\circ}$, which corresponds to the (002) diffraction peak of graphene. This observation verify that PbSe nanoconposite was successfully synthesized and attached on graphene sheet [35].

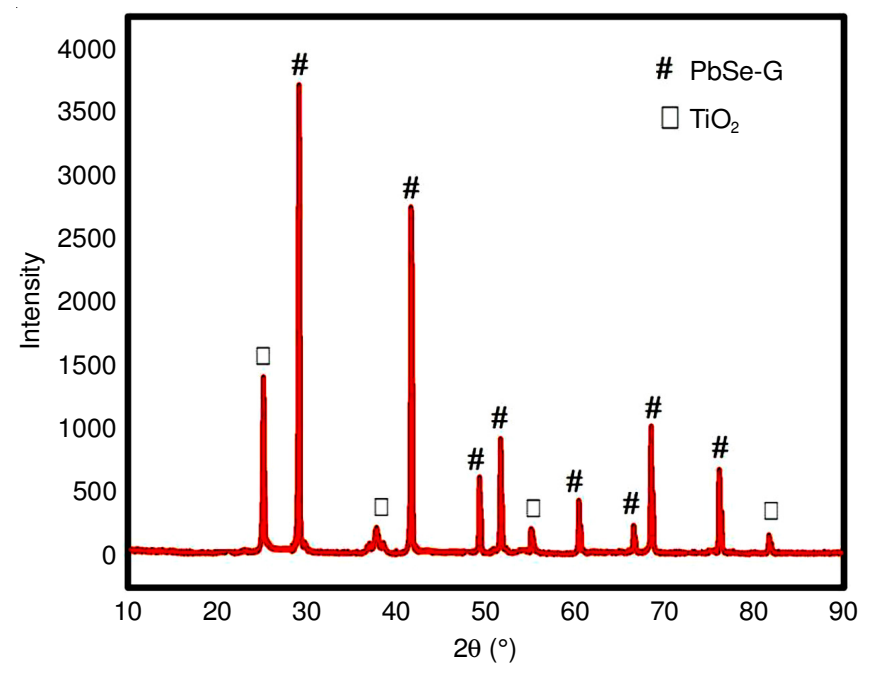

Fig. 1. X-ray diffraction patterns of $\mathrm{PbSe}-\mathrm{G}-\mathrm{TiO}_{2}$ composites

Fig. 2(a-c) show the morphology of the PbSe-G-TiO nanocomposites. The SEM illustrates the overall surface morphology of graphene composites, Fig. 2(a) express that graphene sheet have a flaky texture broken off in different direction and $\mathrm{PbSe}$ nanocomposites unevenly distributed on graphene sheet and the grapahene sheet acts as bridge for $\mathrm{PbSe}$ nanoparticles, which helpful to provide a path for the photogenerated electron and increase photo catalytic efficiency [36]. Fig. 2(b) shows that the $\mathrm{TiO}_{2}$ particles are roughly distributed on grapahene sheet and large interlayer spaces and thin layer edges of graphene can be clearly observed. Fig. 2(c) displays the $\mathrm{PbSe}-\mathrm{G}-\mathrm{TiO}_{2}$ nanocomposites. From the images clearly shows the difference between binary and ternary composites. After attachment of $\mathrm{TiO}_{2}$, the brighter spot arises in the ternary composite suggesting that uniformly dispersed on graphene nanosheet. TEM images of a $\mathrm{PbSe}-\mathrm{G}-\mathrm{TiO}_{2}$ nanocomposite with different magnification (200 $\mathrm{nm}$ to $1 \mu \mathrm{m}$ ) were displayed in the Fig. 3(a-b), which demonstrated the overall history of the $\mathrm{PbSe}$ and $\mathrm{TiO}_{2}$ nanoparticles. From the Fig. 3, it is clearly seen that $\mathrm{PbSe}$ and $\mathrm{TiO}_{2}$ nanoparticles were spherical from and uniformly distributed on the graphene sheet, the average size of $\mathrm{PbSe}$ and $\mathrm{TiO}_{2}$ to be approximately 6-25 and 9-18 nm, respectively. The particle further confirms the uniform distri- 

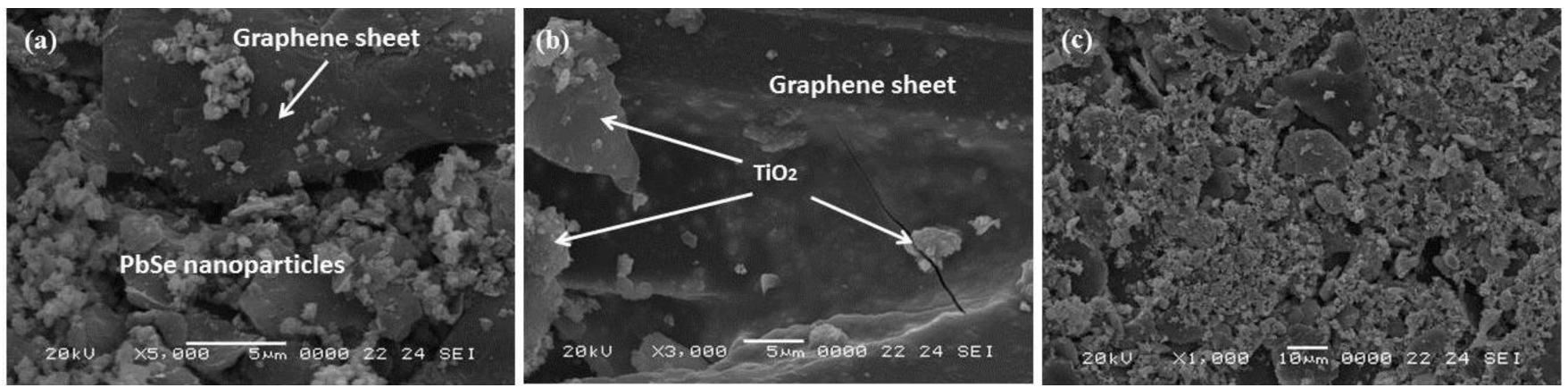

Fig. 2. SEM images of $\mathrm{PbSe}-\mathrm{G}, \mathrm{TiO}_{2}-\mathrm{G}$ and $\mathrm{PbSe}-\mathrm{G}-\mathrm{TiO}_{2}$ composites
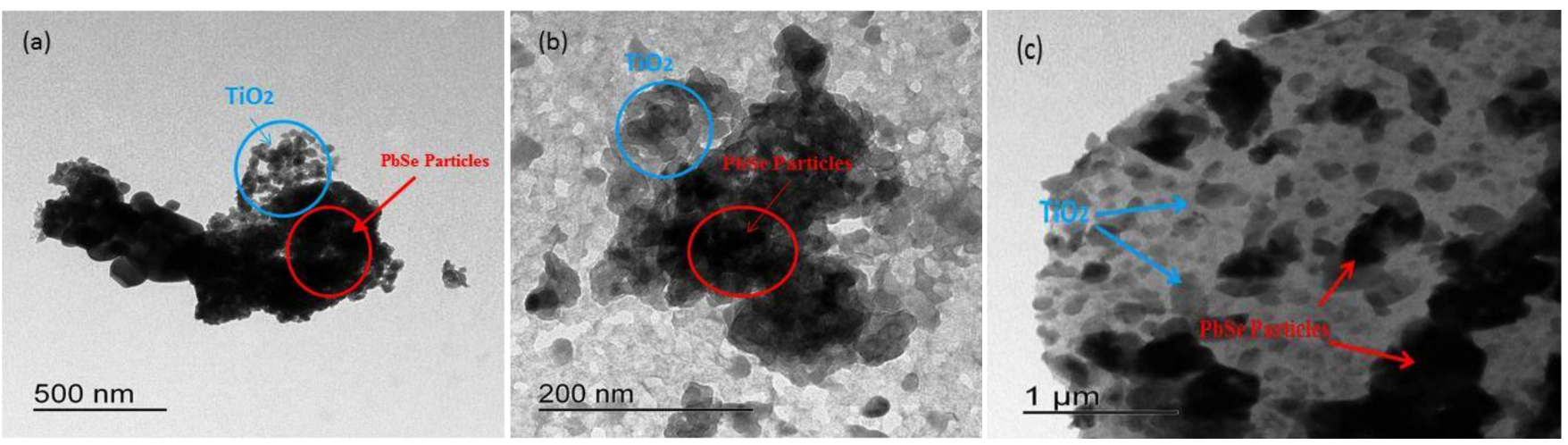

Fig. 3. TEM images of PbSe-G-TiO 2 composites with different magnification

bution and strong heterojunction of $\mathrm{PbSe}$ and $\mathrm{TiO}_{2}$. A spherical and uniform particle size of PbSe further confirm that the presence of GO inhibits the growth of PbSe crystals due to the electrostatic attraction between $\mathrm{Pb}^{+2}$ and negatively charged $\mathrm{GO}$ [37] at initial reaction stage, $\mathrm{Pb}^{2+}$ is reduced to $\mathrm{Pb}$ and $\mathrm{PbSe}$ forms by the reaction $\mathrm{Pb}^{+}, \mathrm{Se}^{-}$[37].

Raman spectroscopy is a highly advance technique to study the structural information of carbon-based materials [38]. The $\mathrm{PbSe}-\mathrm{G}-\mathrm{TiO}_{2}$ was further characterized by Raman scattering spectroscopy techniques. Fig. 4 shows the peaks related to anatase $\mathrm{TiO}_{2}$ are observed in $510-410 \mathrm{~cm}^{-1}$ region [39-41]. The characteristic graphitic peaks, D and $\mathrm{G}$ peak of GO are appear at 1375 and $1585 \mathrm{~cm}^{-1}$ respectively. The $\mathrm{G}$ band appears at the first order scattering of the optical $\mathrm{E}_{2 \mathrm{~g}}$ Phonon of $s p^{2}$ carbon

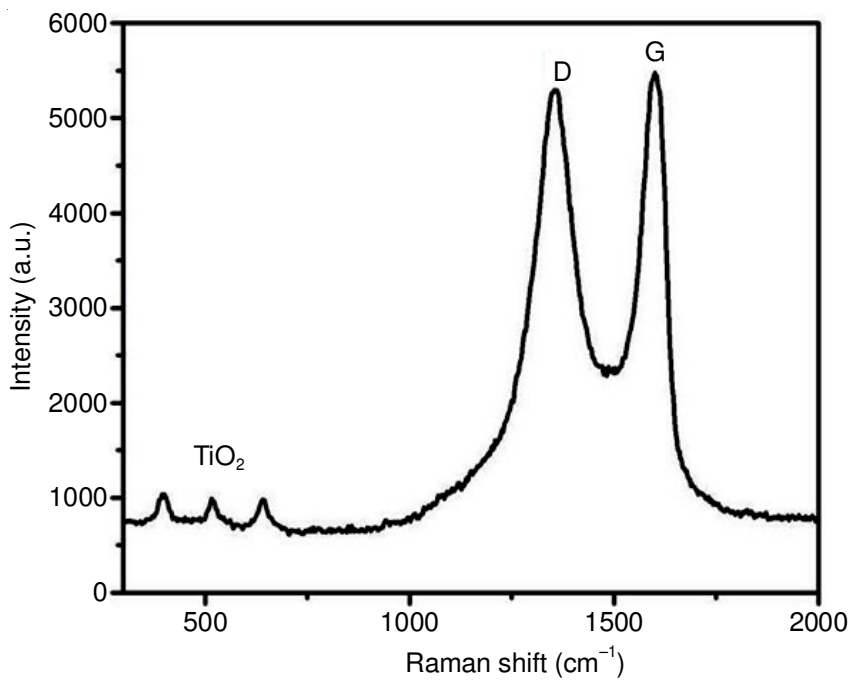

Fig. 4. Raman spectra of $\mathrm{PbSe}-\mathrm{G}-\mathrm{TiO}_{2}$ nanocomposite atoms and $\mathrm{D}$ band comes from $\mathrm{A}_{1 \mathrm{~g}}$ symmetry [42]. These two bands (D $1360 \mathrm{~cm}^{-1}, \mathrm{G} 1590 \mathrm{~cm}^{-1}$ ) indicate an interaction between GO and selenide nanosheets, the nature of the defects can find the ratio intensities of $D$ and $G$ band, the ratio intensities of $G$ and D band approximately 0.965 , which is smaller than graphene oxide. The decreasing ratio is clear evidence of the increased number of graphene layers.

The photocalytic activities of $\mathrm{PbSe}-\mathrm{G}-\mathrm{TiO}_{2}$ nanocomposite using rhodamine $\mathrm{B}$ as organic dye under visible irradiation was explored Fig. 5(a-c). Which shows decreasing intensity of electronic absorption spectra $\left(\lambda_{\max }\right)$ with different interval of time, exhibited that the degradation of rhodamine $\mathrm{B}$ in the presence of $\mathrm{PbSe}-\mathrm{G}-\mathrm{TiO}_{2}$ catalysts. The $\lambda_{\max }$ value of $\mathrm{PbSe}$ G-TiO ${ }_{2}$ was found to $555 \mathrm{~nm}$ and $\mathrm{PbSe}-\mathrm{G}-\mathrm{TiO}_{2}$ ternary nano composite intensity decreased approximately $92.2 \%$ at the end of $180 \mathrm{~min}$ the excellent efficiency attributed due to the three factors: (a) good absorption by $\mathrm{PbSe}-\mathrm{G}-\mathrm{TiO}_{2}$ photocatalyst, (b) fast charge transfer route and (c) graphene acts an adsorption support material and dye absorbs molecules on the surface of graphene via $\pi-\pi$ interaction, Fig. 5(a) demonstrates that the concentration of rhodamine $\mathrm{B}$ change due to the different interval of time, which shows the good absorption efficiency of rhodamine $\mathrm{B}$ of $\mathrm{PbSe}-\mathrm{G}_{-} \mathrm{TiO}_{2}$ nanocomposites. For achieving adsorptiondesorption equilibrium, the prepared sample was kept in dark for $30 \mathrm{~min}$, after obtain the adsorption-desorption equilibrium, the solution was kept in closed box and turn on visible light. The solution was irradiated for $30 \mathrm{~min}$ and every $30 \mathrm{~min}$ sample was taken out from the chamber for further syntheses. Then the sample was centrifuge and find dye concentration using UV-visible spectrometer. The photo catalytic performance of different product was estimated under visible light irradiation. Figs. 5(a-c) show the photocatalytic degradation of different 
samples with different interval of time. It shows that the photocatalytic degradation performance of $\mathrm{PbSe}-\mathrm{G}-\mathrm{TiO}_{2}$ nanocomposites are higher than that $\mathrm{PbSe}-\mathrm{G}$ and $\mathrm{TiO}_{2}-\mathrm{G}$. During the passage of the time, the intensity of the characteristic absorption band of rhodamine B $(555 \mathrm{~nm})$ was significantly decreasing and after $180 \mathrm{~min}$ approximately $92.2 \%$ of the organic dye was degraded. Moreover, kinetic of the degradation can be express as:
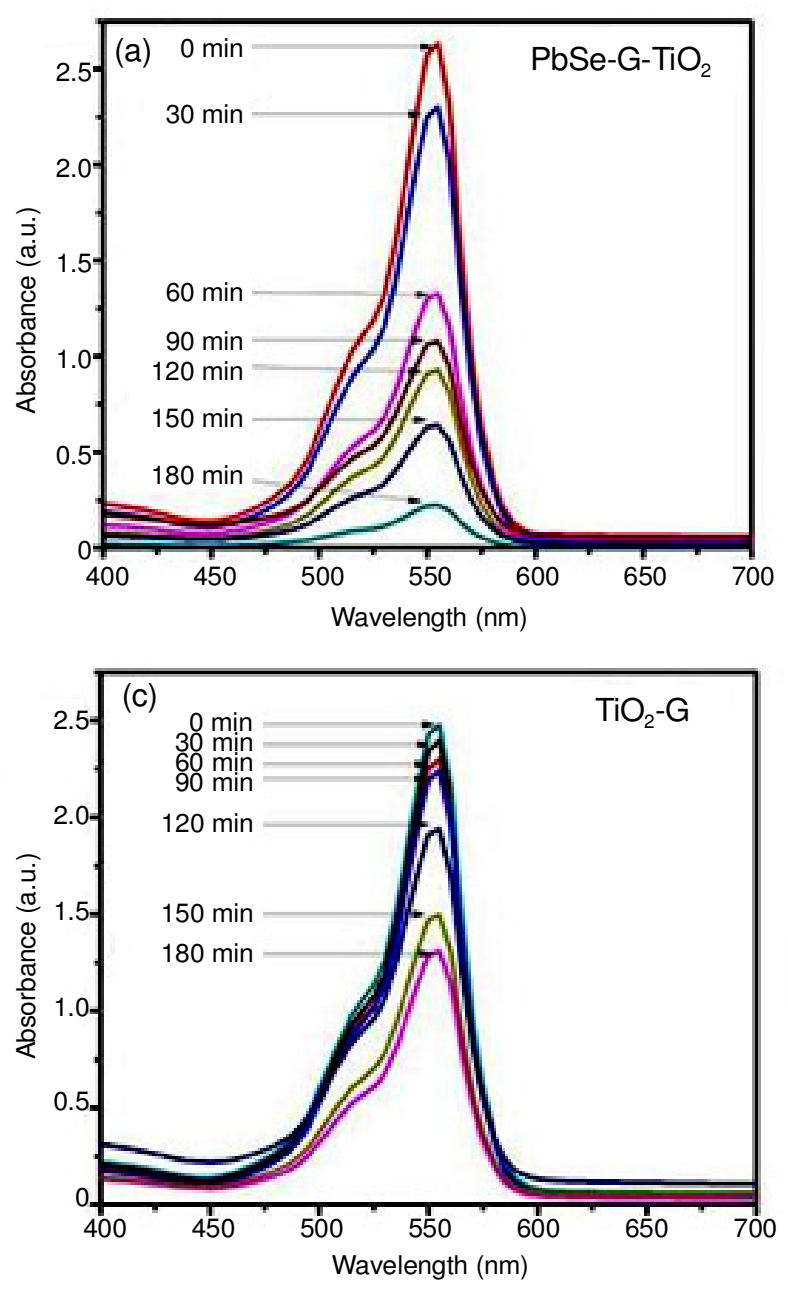

$$
-\ln \left(\mathrm{C}_{\mathrm{t}} / \mathrm{C}_{\mathrm{o}}\right)=\mathrm{K}_{\mathrm{appt}}
$$

$\mathrm{K}_{\text {appt }}$ is apparent rate constant and $\mathrm{C}_{\mathrm{o}}$ initial concentration at $\mathrm{t}$ $=0$ and $\mathrm{C}_{\mathrm{t}}$ are the concentration of dye at $\mathrm{t}=\mathrm{t}[43]$. The kinetic plot and apparent rate constant $\left(\mathrm{K}_{\text {aap }}\right)$ (slop of the) in each case was shown in Fig. 5(d). It can be clearly seen that PbSe-G$\mathrm{TiO}_{2}$ ternary nanocomposite photo catalytic efficiency is almost 6 times higher than pure $\mathrm{TiO}_{2}$. The recycling of catalysts is most important steps to estimate the practical application of photo-
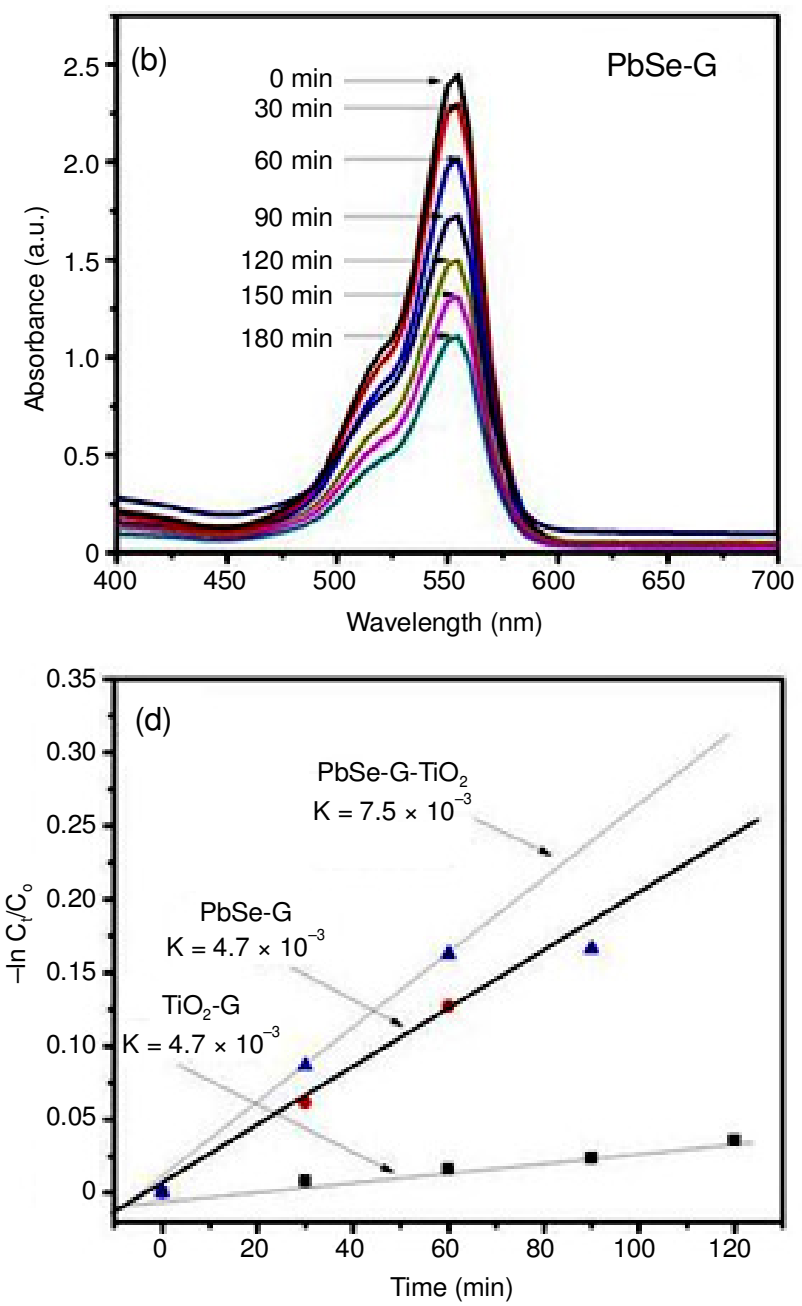

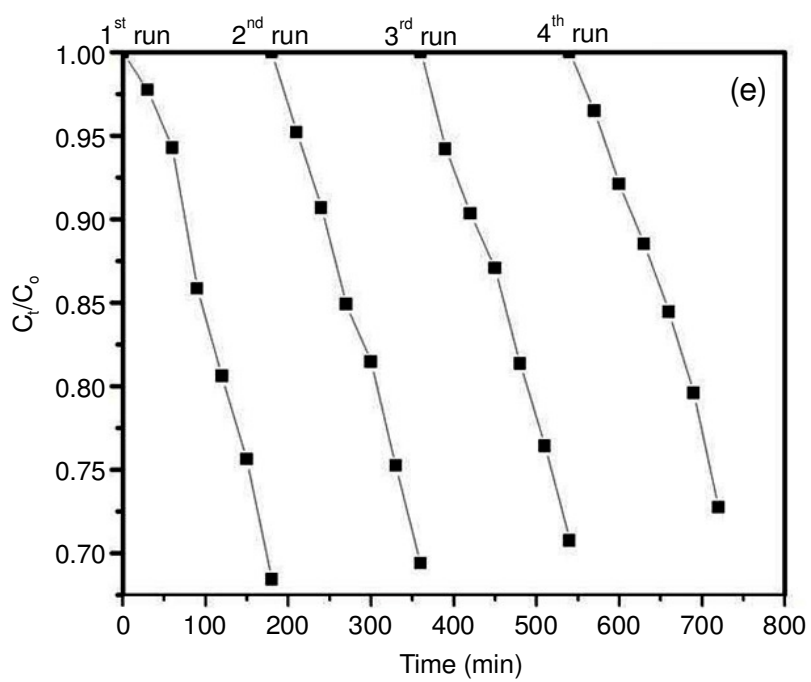

Fig. 5. Time-dependent absorption spectra of rhodamine $\mathrm{B}$ under visible light using (a) $\mathrm{PbSe}-\mathrm{G}-\mathrm{TiO}_{2},(\mathrm{~b}) \mathrm{PbSe}-\mathrm{G}$, (c) TiO ${ }_{2}-\mathrm{G}$, (d) kinetics of degradation of prepared composites under visible light irradiation and (e) recyclability of a $\mathrm{PbSe}-\mathrm{G}-\mathrm{TiO}_{2}$ nanocomposite 
catalysts. After four times recycling, it is clearly seen that the $\mathrm{PbSe}-\mathrm{G}-\mathrm{TiO}_{2}$ nanocomposite did not show any significant loss of photocatalytic activity (Fig. 5e). Hence a $\mathrm{PbSe}-\mathrm{G}_{-} \mathrm{TiO}_{2}$ ternary nanocomposite shows great ability and therefore it is a promising candidate for environmental mediation.

\section{Conclusion}

In summary, $\mathrm{PbSe}-\mathrm{G}_{-} \mathrm{TiO}_{2}$ ternary nanocomposites were successfully synthesized by ultrasonic techniques for the photocatalytic degradation activity. Further $\mathrm{PbSe}-\mathrm{G}-\mathrm{TiO}_{2}$ was characterized by XRD, SEM, TEM and RAMAN. The photocatalytic performance of $\mathrm{PbSe}-\mathrm{G}-\mathrm{TiO}_{2}, \mathrm{PbSe}-\mathrm{G}$ and $\mathrm{TiO}_{2}-\mathrm{G}$ were evaluated using rhodamine $\mathrm{B}$. It is clearly exhibited that $\mathrm{PbSe}-\mathrm{G}-\mathrm{TiO}_{2}$ ternary nanocomposite can used as a promising photocatalyst for the removing hydrophobic dyes. This work opens a new route to utilize graphene-based ternary nanocomposites for the energy and environmental-related applications.

\section{REFERENCES}

1. A. Khataee, M. Sheydaei, A. Hassani, M. Taseidifar and S. Karaca, Ultrason. Sonochem., 22, 404 (2015); https://doi.org/10.1016/j.ultsonch.2014.07.002.

2. J. Wang, T. Ma, Z. Zhang, X. Zhang, Y. Jiang, Z. Pan, F. Wen, P. Kang and P. Zhang, Desalination, 195, 294 (2006); https://doi.org/10.1016/j.desal.2005.12.007.

3. N.J. Bejarano-Pérez and M.F. Suárez-Herrera, Ultrason. Sonochem. 14, 589 (2007); https://doi.org/10.1016/j.ultsonch.2006.09.011.

4. Z.-D. Meng and W.-C. Oh, Ultrason. Sonochem., 18, 757 (2011); https://doi.org/10.1016/j.ultsonch.2010.10.008

5. R. Pelegrini, P. Peralta-Zamora, A.R. de Andrade, J. Reyes and N. Duran, Appl. Catal. B, 22, 83 (1999);

https://doi.org/10.1016/S0926-3373(99)00037-5.

6. A. Konsowa, M. Ossman, Y. Chen and J.C. Crittenden, J. Hazard. Mater. 176, $181(2010)$ https://doi.org/10.1016/j.jhazmat.2009.11.010.

7. S. Won, S. Choi, B. Chung, D. Park, J. Park and Y.-S. Yun, Ind. Eng. Chem. Res., 43, 7865 (2004); https://doi.org/10.1021/ie049559o.

8. Y.M. Slokar and A. Majcen Le Marechal, Dyes Pigments, 37, 335 (1998); https://doi.org/10.1016/S0143-7208(97)00075-2.

9. Y. Xu, R.E. Lebrun, P.-J. Gallo and P. Blond, Sep. Sci. Technol., 34, 2501 (1999); https://doi.org/10.1081/SS-100100787.

10. R. Ahmad, P.K. Mondal and S.Q. Usmani, Bioresour. Technol., 101, 3787 (2010); https://doi.org/10.1016/j.biortech.2009.12.116.

11. V. Gupta and Suhas, J. Environ. Manage., 90, 2313 (2009); https://doi.org/10.1016/j.jenvman.2008.11.017.

12. M.-S. Wu, T.-C. Wen and A. Gopalan, Mater. Chem. Phys., 74, 58 (2002); https://doi.org/10.1016/S0254-0584(01)00406-0.

13. Y. Zhang, Q. Li, L. Sun, R. Tang and J. Zhai, J. Hazard. Mater., 175, 404 (2010); https://doi.org/10.1016/j.jhazmat.2009.10.019.

14. P. Lv, M. Zheng, X. Wang and F. Huang, J. Alloys Comp., 583, 285 (2014); https://doi.org/10.1016/j.jallcom.2013.07.156.

15. H.M. Yadav and J.-S. Kim, J. Alloys Comp., 688, 123 (2016); https://doi.org/10.1016/j.jallcom.2016.07.133.

16. Y. You, S. Zhang, L. Wan and D. Xu, Appl. Surf. Sci., 258, 3469 (2012); https://doi.org/10.1016/j.apsusc.2011.11.099.

17. F. Deng, Y. Li, X. Luo, L. Yang and X. Tu, Colloids Surf. A, 395, 183 (2012); https://doi.org/10.1016/j.colsurfa.2011.12.029.

18. J. Yu, Q. Xiang and M. Zhou, Appl. Catal. B, 90, 595 (2009); https://doi.org/10.1016/j.apcatb.2009.04.021.
19. G. Liu, M. Zhang, D. Zhang, J. Zhou, F. Meng and S. Ruan, J. Alloys Comp., 616, 155 (2014); https://doi.org/10.1016/j.jallcom.2014.07.147.

20. S. Bouhadoun, C. Guillard, F. Dapozze, S. Singh, D. Amans, J. Bouclé and N. Herlin-Boime, Appl. Catal. B, 174-175, 367 (2015); https://doi.org/10.1016/i.apcatb.2015.03.022.

21. R. Asahi, T. Morikawa, T. Ohwaki, K. Aoki and Y. Taga, Science, 293, 269 (2001); https://doi.org/10.1126/science.1061051.

22. Y.-C. Wu and L.-S. Ju, J. Alloys Comp., 604, 164 (2014); https://doi.org/10.1016/j.jallcom.2014.03.023.

23. J. Lei, Y. Chen, F. Shen, L. Wang, Y. Liu and J. Zhang, J. Alloys Comp., 631, 328 (2015); https://doi.org/10.1016/j.jallcom.2015.01.080.

24. M. Wang, L. Sun, Z. Lin, J. Cai, K. Xie and C. Lin, Energy Environ. Sci., 6, 1211 (2013); https://doi.org/10.1039/c3ee24162a.

25. L.-L. Tan, W.-J. Ong, S.-P. Chai and A.R. Mohamed, Nanoscale Res. Lett., 8, 465 (2013); https://doi.org/10.1186/1556-276X-8-465.

26. C. Stampfer, E. Schurtenberger, F. Molitor, J. Guttinger, T. Ihn and K. Ensslin, Nano Lett., 8, 2378 (2008); https://doi.org/10.1021/n1801225h.

27. K. Haubner, J. Murawski, P. Olk, L.M. Eng, C. Ziegler, B. Adolphi and E. Jaehne, ChemPhysChem, 11, 2131 (2010); https://doi.org/10.1002/cphc.201000132.

28. F. Lupo, R. Kamalakaran, C. Scheu, N. Grobert and M. Rühle, Carbon, 42, 1995 (2004); https://doi.org/10.1016/j.carbon.2004.03.037

29. X.-Y. Zhang, H.-P. Li, X.-L. Cui and Y. Lin, J. Mater. Chem., 20, 2801 (2010); https://doi.org/10.1039/b917240h.

30. A.Z. Abdullah and P.Y. Ling, J. Hazard. Mater., 173, 159 (2010); https://doi.org/10.1016/j.jhazmat.2009.08.060.

31. K. Ullah, S. Ye, S.-B. Jo, L. Zhu, K.-Y. Cho and W.-C. Oh, Ultrason. Sonochem., 21, 1849 (2014); https://doi.org/10.1016/j.ultsonch.2014.04.016.

32. T. Ghosh and W. Oh, J. Photocatal. Sci., 3, 17 (2012).

33. M.A. Mahdy, I.A. Mahdy and E. Mahmoud, Physica E, 59, 117 (2014); https://doi.org/10.1016/j.physe.2014.01.009.

34. L. Zhu, T. Ghosh, C.-Y. Park, Z.-D. Meng and W.-C. Oh, Chin. J. Catal., 33, 1276 (2012); https://doi.org/10.1016/S1872-2067(11)60430-0.

35. S.D. Perera, R.G. Mariano, K. Vu, N. Nour, O. Seitz, Y. Chabal and K.J. Balkus Jr., ACS Catal., 2, 949 (2012); https://doi.org/10.1021/cs200621c.

36. L. Yoong, F.K. Chong and B.K. Dutta, Energy, 34, 1652 (2009); https://doi.org/10.1016/j.energy.2009.07.024.

37. D. Li, M.B. Müller, S. Gilje, R.B. Kaner and G.G. Wallace, Nat. Nanotechnol., 3, 101 (2008); https://doi.org/10.1038/nnano.2007.451

38. J.-J. Zhang, X. Liu, T. Ye, G.-P. Zheng, X.-C. Zheng, P. Liu and X.-X. Guan, J. Alloys Comp., 698, 819 (2017); https://doi.org/10.1016/i.jallcom.2016.12.279.

39. T. Tanaka, T. Sueishi, K. Saito, Q. Guo, M. Nishio, K.M. Yu and W. Walukiewicz, J. Appl. Phys., 111, 053522 (2012); https://doi.org/10.1063/1.3691964.

40. M. Ishii, K. Shibata and H. Nozaki, J. Solid State Chem., 105, 504 (1993); https://doi.org/10.1006/jssc.1993.1242.

41. P. Falaras, P. Papazafiri and P. Kitsiou, Int. J. Nanomed., 9, 3219 (2014).

42. R.-C. Wang, Y.-C. Chen, S.-J. Chen and Y.-M. Chang, Carbon, 70, 215 (2014); https://doi.org/10.1016/j.carbon.2013.12.110.

43. J. Kyriakopoulos, M.D. Tzirakis, G.D. Panagiotou, M.N. Alberti, K.S. Triantafyllidis, S. Giannakaki, K. Bourikas, C. Kordulis, M. Orfanopoulos and A. Lycourghiotis, Appl. Catal. B, 117-118, 36 (2012); https://doi.org/10.1016/j.apcatb.2011.12.024. 